\title{
Getting quality in qualitative research: A short introduction to feminist methodology and methods
}

\author{
Maeve Landman \\ Faculty of Humanities, Languages and Social Sciences, University of the West of England, Frenchay Campus, \\ Coldharbour Lane, Bristol BS16 1QY, UK
}

\begin{abstract}
The present paper reflects a practical activity undertaken by the Nutrition Society's qualitative research network in October 2005. It reflects the structure of that exercise. First, there is an introduction to feminist methodology and methods. The informing premise is that feminist methodology is of particular interest to practitioners (professional and/or academic) engaged in occupations numerically dominated by women, such as nutritionists. A critical argument is made for a place for feminist methodology in related areas of social research. The discussion points to the differences that exist between various feminist commentators, although the central aims of feminist research are broadly shared. The paper comprises an overview of organizing concepts, discussion and questions posed to stimulate discussion on the design and process of research informed by feminist methodology. Issues arising from that discussion are summarized.
\end{abstract}

Feminist methodology and methods: Social reality: Lived experience

\section{Background}

The workshop reported here was part of a programme focused on qualitative research methods. As stated in the network convenor's introductory remarks, the importance of sustained professional attention to this area rests on the imperatives for competency in qualitative research methods now expected of public health practitioners. This is the better to establish the foundation for the participatory, transformative work in community development that the current policy context demands. In this context, nutritionists grapple with the challenges of quality in qualitative research, as do other health professionals. The workshop provided an opportunity to engage with a philosophy underpinning qualitative research methods and methodology, drawing on the presenter's experience of teaching feminist research methodology and methods within a postgraduate programme for health professionals. Specifically, such competence requires a critical understanding that the nature of evidence, for the development of policy and practice that are effective, should take account of lived experience that cannot be captured in experiments or trials; i.e. to generate understanding of the attitudes, challenges, aspirations, uncertainties and emotions contexts that inform decisions about food and feeding. Nutritionists, therefore, are increasingly required to engage with broader definitions of evidence; that which is context-sensitive and associated with social science-oriented research (Canadian Health Services Research Foundation, 2005). In the present workshop the focus was on the contributions of feminist methodology to the enterprise of building quality in generating evidence about the lived experience of women; the informing premise is that social realities are gendered and, in the interests of context-sensitive evidence, this factor has to be acknowledged at all stages of the research process.

\section{Introduction: clarifying terms}

The primary site of interest here is methodology; its meaning should be distinguished from method or methods, although these concepts are all clearly linked. According to Ramazanoglu (2002) methodology 'comprises rules that specify how social investigation should be approached.' Methodological debates in social scientific research refer to attempts at clarification as to its nature and purpose, and therefore are concerned with procedures for making knowledge valid and authoritative. The debates range from critical discussions relating to science, truth and epistemology (i.e. the study of procedures for the creation of publicly-validated knowledge) to details of field practice 
(for reviews, see Stanley \& Wise, 1993; Ramazanoglu, 2002; see also citations in Letherby, 2004a,b; Oakley, 2004; these were papers circulated for the workshop). Methodology sets out the theoretical framework that will inform the research process. Harding (1987) suggests that 'methodology is a theory and analysis of how research does and should proceed', which necessarily involves consideration of disciplinary method, i.e. modes of explanation, understanding and the nature of abstraction (Sayer, 1992; according to Ramazanoglu (2002) 'method' indicates a general approach to social science, as in "empirical method', 'scientific method' or 'Marxist method'). Finally, a method (or methods) here refers to familiar techniques of data generation that include the interview, focus groups, observation and case study.

Feminist methodology is specifically concerned with how, or whether, knowledge produced about social life can be connected with the social realities of women in the context of any methodology that is dominated by men and that neglects consideration of the gendered nature of social life. Of particular interest, in the context of the present workshop, social practices associated with food and feeding are highly gendered, as the literature shows (for example, see Charles \& Kerr, 1988; Lupton, 1996). These methodological challenges encompass consideration of which research methods may be more effective than others in reflecting the lived experience of women. It is for this very point that the workshop participants were asked to consider the work of Oakley (1981), who argues for reciprocity between the researcher and the researched in the qualitative research interview, based on her experience of working with women.

Feminist methodology is informed by feminist epistemology; in particular, who can be agents of knowledge, what can be known and how knowledge is validated, and the relationship between knowing and being (ontology). Feminists are concerned with the implications of the exclusion of women's knowledge and experience of the traditional male constructions of knowledge. In biomedicine, for example, Klinge \& Bosch (2005) observe that feminist involvement came in response to the way in which women were treated in the medical establishment in the 1970s. As these authors observe, what emerged was the exposure of the "male norm in research and treatment ... [which was critiqued in terms of the]... medicalization, psychologization and trivilialization of women's symptoms'. However, case studies that acknowledged the processes of gender did not seem markedly to transform everyday research practices in the life sciences and biomedicine, and the authors develop an argument for gender-sensitive research that will lead to more adequate data which serve the health interests of both women and men. The gender disparity highlights the need for continued pressure from feminist methodology, the better to reveal and understand experiences of women in contemporary society and adequately address their needs, thus challenging the partial accounts of the gendered lives of both women and men. This objective, broadly, is the agenda for feminist research.

The range of questions raised by practitioners of feminist epistemology is concerned with the dominant
Table 1. Features of feminist research

Feminist research accounts are:

1. derived from experience analytically entered into by enquiring feminists (rather than theory preceding analysis of experience);

2. continually subject to revision in the light of women's experience, and so recognise that this experience varies over space and time;

3. reflexive and self-reflexive, accessible to everyone and 'not just to theoreticians as a special kind of person';

4. not rendered sacrosanct and enshrined in 'texts, to be endlessly pored over like chicken entrails', which would limit the impact of feminist scholarship on the lives over women outside the academy.

conceptualizations and practices of science and the scientific method. Feminist epistemology questions whether mainstream conceptions of objectivity, knowledge and reason proceed from a view of the social world only from the perspective of male or masculine values, interests, emotions and attitudes (i.e. reflect an androcentric perspective). It asks how the conceptual frameworks of particular sciences could be reconfigured to reflect women's interests.

Feminist scholarship gained ground as a part of 'secondwave feminism' in the 1970s and 1980s (the first wave having occurred at the beginning of the twentieth century, popularly associated with the suffragette movement). The advance of feminist philosophy and theory informed methodological discussions. Stanley \& Wise (1990) argue for theory with the features set out in Table 1 .

Harding (1987) focuses on feminist epistemology as the basis for the development of method and methodology, and identifies two epistemologies: feminist standpoint; feminist empiricism. Feminist standpoint epistemology serves as a foundation for a methodology for feminist research that is located in, and proceeds from, a grounded analysis of women's material realities. Because it proceeds thus, it is more radical, more complete and less distorted than theory proceeding from male-dominated method. Superior 'truer' knowledge is thus derived from a committed feminist exploration of women's experiences. These ambitions are achieved by engagement in intellectual and political struggle, which is justifiable because it is necessary to see natural and social life from the point of view of the activity that produces women's social experiences, often overlooked or judged to be inferior and trivial. This approach, then, sees beyond the partial perspectives available from the dominant gender, i.e. from the experience of men.

Feminist empiricism is concerned with feminist responses to biases and problems in traditional disciplines. Crucially, context of discovery (the point of the identification of the social phenomenon or entity for study) is as important in the construction and presentation of knowledge. It recognises that the scientific method is insufficient as a means of eliminating overt sexism and covert androcentrism. On this view, mainstream (rendered 'malestream') research 'norms' contribute to feminist research problems. 
Table 2. Characteristics of Harding's (1987) feminist standpoint

A feminist standpoint:
1. explores relationships between knowledge and power;
2. deconstructs the 'knowing feminist';
3. is grounded in women's experience and recognises the role of
emotions and gendered embodiment;
4. takes into account diversity of women's experiences and the
interconnected power relationship between women;
5. acknowledges that knowledge is always partial.

More recently, Ramazanoglu (2002) has discussed feminist standpoint theories as explorations of difficulties of establishing relationships between knowledge and power, in the context of challenges to traditional truth claims, while still being able to give valid accounts of gendered lives. She identified five key characteristics of a feminist standpoint (while acknowledging that any summary cannot adequately encompass all versions); these characteristics are set out in Table 2 .

There are, then, different emphases among various epistemological endeavours. Stanley \& Wise (1990) identify five sites for feminism in the research process, as featured in Table 3. The broad aims remain congruent with those of other critical commentators. On this basis, feminist methodology is summarized in the form of the basic tenets for feminist research accounts shown in Table 4.

This overview of feminist methodology sets the context for the next consideration: feminist research methods.

\section{Are there feminist research methods?}

As mentioned earlier, Oakley (1981) argued for the value of the in-depth qualitative interview for feminist research. In an article that remains important in current debates, Oakley (1981) wrote of the inadequacies of the social science methodology textbook proscriptions for the research interview as part of a survey. She cites a version in which the interviewer is a tool or an instrument, and that also extols the necessity for distance from the respondent in the interests of objectivity, to strike a rapport but remain aloof. Her observations came from her study, the Transition to Motherhood Project, which had a conventional research design and involved 178 interviews over 12 months. Oakley (1981) notes that the research processes affected

Table 3. Five sites for feminism in the research process

The sites identified by Stanley \& Wise (1990) are in:

1. the recognition of emotion as a research experience;

2. the intellectual autobiography of researchers, who bring values and particular dispositions to the research experience;

3. the management of the differing realities and understandings of the researcher and researched;

4. the complex question of power in research and writing, including questions of who owns the data and to what extent respondent validation should influence publication and dissemination.
Table 4. Tenets for feminist research accounts

Feminist research:
1. asserts that consciousness-raising is a legitimate way of
seeing and is therefore a methodological tool;
2. espouses a reflexive concern with gender as all pervasive;
3. challenges objectivity; rejects the distinction from subjectivity,
and the exclusion of experience and emotion as unscientific;
4. has specific ethical concerns, particularly with women as
5. is acknowledged as a political activity.

the women she interviewed, and she made a record of their questions of her (878 in all), including: requests for information (for their own situation); about the research; about Oakley herself (e.g. Did you breast feed?); on particular matters (e.g. How do you cook an egg for a baby?). Her reflections of the process led her to conclude that the feminist researcher proceeding from the tenet that the research is for women, should revise the process. Instead, she sets out the case for an alternative process (see Table 5).

Oakley (1981) argues that a feminist methodology of social science requires that this rationale is not confined to feminist research but is discussed in social research more generally. As has been indicated, this call has had an important impact in methodological debates that have been widely taken up and continue to shape developments in social research, as will be seen later.

The effects of these arguments bear upon conceptualisations of methodology and, therefore, upon research practice. The challenge to claims of neutrality in the research process (from inception to publication) is not confined to feminist scholars. Other researchers argue that validity and reliability in social research have to be understood within its own parameters rather than those of the natural sciences: human research subjects respond to the process of the research, which creates its own unique dynamic that cannot be replicated in other places and at other times. Researchers approach the task with certain values and predispositions; in the early 1970s, Becker (1971) remarked, for the benefit of sociologists, that 'the question is not whether we should take sides, since we inevitably will, but rather whose side are we on'. In these circumstances the ethical imperative is to make clear what those values and predispositions are; as has

Table 5. Oakley's (1981) femininist approach to the research interview

In this approach:

1. the interviewer presents her own identity in the process, not only asking questions, but also sharing knowledge;

2. reciprocity invites an intimacy that encourages revelations from the researched relating to her material reality;

3. develops a participatory model of research that challenges power relationships between researcher and researched;

4. produces work that challenges prevailing stereotypes of the researcher and the researched. 
been seen, some feminist researchers argue for an explicitly political research programme.

\section{The debate continues ....}

Oakley (1996) goes on to argue that the language of 'qualitative' and 'quantitative' methods used currently is the outcome of a deeply gendered history across both the social and natural sciences' (Oakley, 2004). On the question of whether there are distinctively feminist research methods, specifically the interview, Letherby (2004b) returns to the original debate in order to raise other concerns from her own experience and with reference to reflections on Oakley's (2004) arguments. In summary, Letherby (2004b) broadly draws from feminist research literature to argue that the qualitative research interview cannot be so claimed. Instead, she observes that a friendly interviewer encourages private revelations in the course of the dialogue. Moreover, she points to the possibility that respondents need to know how to protect themselves from interviewers and that it may be patronising to suggest that what respondents want in return is reciprocity for their engagement in the exercise. She warns that it is important that assumptions about the nature of power in the research process are not taken for granted; for power passes between researcher and respondent during the process. Indeed the research respondent is arguably very powerful, for it is she who holds the data, although the balance shifts when the process of data generation is completed. In relation to a woman researcher interviewing women, Letherby (2004a) highlights the point that 'women' is not a homogenous category, but that women are divided by other variables (of which, socio-economic status and ethnicity are among the most important). Finally, she refers to wider discussions to point out that any appeal to the generation of better data on the basis of sisterhood 'is a simplistic view of feminist research'. In her response to Letherby (2004a), Oakley (2004) points out that the over-riding consideration for choosing a particular method for data generation is that it should fit the research design. As will be seen, the guiding questions in Table 6 show that research need not be labelled 'feminist' in order properly to be gender sensitive.

The aim of feminist research to gain a clearer and better understanding of social reality by ending the marginalization of women's lived experience in social science has served further developments elsewhere. These aspirations are generalizable and are reflected in some specific social research, informed by feminist methodology, by and for oppressed groups whose lives and experiences would otherwise be rendered invisible or only partially rendered; for example, ethnic groups such as Maori in New Zealand (Bishop, 1998) and gay and lesbian groups (for example, see Plummer, 1994).

\section{Lessons from feminist methodology}

The issues for research design that will be highlighted develop the theme of careful and responsible research design. In Oakley's (1996) words, the audit trail through
Table 6. Workshop practical: guiding questions (after Ramazanoglu, 2004)
Research design: some questions
Is the research population entirely or predominantly women?
(a) Is this significant? In what way?
Is the gendered nature of social life accounted for in the framing of the 'problem'?

(a) Does it need to be? If not, why not?

Is the context domestic, private (home-making, childcare) or professional, public (feminised workforce or workplace)? Is the 'the interaction order' gendered?

Are the methods appropriate, i.e. sensitive to the gendered nature of the context? (qualitative research seeks to tap into the subjective understandings of social actors)

Revisit research aims: what is the nature of the social reality to be investigated?

(a) How best can knowledge of that reality be obtained?

\section{Reflexivity}

Is the social identity of the researcher implicated in the selection of 'the problem'? In the conduct of inquiry?

What is the nature of the researched-researcher relationship?

What is the research contract?

research question, methods, data collection, analysis and interpretation needs to be clear, systematic and explicit. Far from selecting a method because of its capacity for service in the feminist research cause, it behoves all researchers to contemplate the exploitative potential of interview method that remains; researchers benefit from a process that is based on some form of contract, and questions of power, advantage, reciprocation and recognition of time and effort are seemly. Also, research that recognises feminist precepts is not necessarily exclusively qualitative: some researchers argue that quantitative instruments, properly designed, could be potentially less harmful to respondents and more useful to policy makers. Letherby (2004a) points out that the use of qualitative research is not the only legitimate feminist approach, and advocates variety and diversity in feminist methods. She calls for a mix of old and new: interviews and questionnaires; content analysis of public and private documents; action research; multi-method approaches; drama; autobiography; group diaries, etc. She also warns that the myth that feminists 'only do interviews' persists, and compounds sexist views about women as good listeners and men alone having numerical skills, while the emotional work of both men and women is ignored. This last point is important, because to get to the neglected aspects of social research (the private, the emotional and the subjective in women's social realities), in turn leads the reflexive practitioner to reflect on whether and when these aspects of men's social realities are investigated.

Beyond the moral and ethical considerations of the research process, Lee-Treweek \& Linkogle (2000) refer to relationships within research projects that are often staffed by postgraduate students, and junior staff often on fixed-term contracts, many of whom are women. It is argued that concerns about disparity of power and status should not be limited to critical discussions about researchers and participants. Along with the treatment of 
students, and particularly postgraduates, the research management issues require critical ethical scrutiny.

\section{Discussion: the implications for practice}

This review set the scene for a workshop exercise, centred on rethinking research and professional practice that overtly acknowledges the gendered nature of social realities in general and of food and feeding practices in particular. This exercise requires making strange the familiar taken-for-granted situations that professionals encounter everyday; it certainly means coming to grips with the vocabulary of social science, and especially that concerned with the gendered nature (an example of that lexicon) of social realities. Thus, instead of thinking of simply talking to research respondents and clients, the interaction order is considered instead, together with the ways in which it may be critically examined to reveal how: (1) situated discourse is gendered; (2) specifically, what can be learned about a woman's lived experience and about women's social experiences. This aspect, in the absence of proper analytical attention, as has been seen in the earlier overview, is often overlooked or held to be inferior and trivial. This approach entails reflexivity; in other words, there is a self-conscious continuous process of action-reviewrevision as both clinical or research practitioners incorporate gender awareness in the first stages of planning a project, as Oakley (2004) has argued. To this end, the group-work exercise in the workshop addressed the task of devising a research plan from the perspectives introduced in the discussion about the nature of feminist methodology. The point is not that there are distinctive feminist research methods, but that feminist methodology offers much in terms of improving and extending the quality of evidence, specifically in relation to women's social realities; especially in spheres in which they are the primary social actors, as in the many social practices associated with food and nutrition. This approach is entirely congruent with the demand for context-sensitive research. Table 6 sets out the questions designed to promote discussion about the reflexivity as described.

\section{Last word}

An interesting point that emerged during the workshop was the perception of several participants that feminist research was the preserve of aggressive women who are implacably hostile to men and who eschew conventional expressions of femininity in favour of de-sexualised presentations of self. There are many kinds of feminism, but none that conform wholly to this caricature, and there is much to be learned from the fact that it survives among committed and intellectually curious professionals; although, in this case, clearly ready to revise their views and review their prejudices. Feminist research, as has been seen, is grounded in women's experience and recognises the role of emotions and gendered embodiment. A critical understanding of social reality that this approach engenders informs policy and practice for informed decision and for the benefit of a fair and equitable service for all in the communities that public health nutritionists serve.

\section{References}

Becker H (1971) Sociological Work: Method and Substance. London: Allen Lane.

Bishop R (1998) Freeing ourselves from neo-colonial domination in research: A Maori approach to creating knowledge. Qualitative Studies in Education 11, 199-219.

Canadian Health Services Research Foundation (2005) Conceptualizing and Combining Evidence for Health System Guidance. Ottawa, Ont.: CHSRF/FCRSS.

Charles N \& Kerr M (1988) Women, Food and Families: Power, Status, Love, Anger. Manchester: Manchester University Press.

Harding S (editor) (1987) Is there a feminist research method? In Feminism and Methodology, pp. 1-14. Bloomington, IN: Indiana University Press.

Klinge I \& Bosch M (2005) State of the art: transforming research methodologies in EU life sciences and biomedicine: Gender-sensitive way of doing research. European Journal of Women's Studies 12, 377-395.

Lee-Treweek G \& Linkogle S (2000) Danger in the Field: Risk and Ethics in Social Research. London: Routledge.

Letherby G (2004a) Quoting and counting: An autobiographical response to Oakley. Sociology 38, 175-189.

Letherby G (2004b) Reply to Anne Oakley. Sociology 38, 193-194.

Lupton D (1996) Food Body and the Self. London: Sage.

Oakley A (1981) Interviewing women: a contradiction in terms. In Doing Feminist Research, pp. 30-61 [H Roberts, editor]. London: Routledge.

Oakley A (1996) Gender methodology and people's ways of knowing: some problems with feminism and the paradigm debate in social science. Sociology 32, 707-732.

Oakley A (2004) Response to 'Quoting and counting: An autobiographical response to Oakley'. Sociology 38, 191-192.

Plummer K (1994) Telling Sexual Stories: Power, Change and Social Worlds. London: Routledge.

Ramazanoglu C (2002) Feminist Methodology: Challenges and Choices. London: Sage.

Sayer A (1992) Method in Social Science: A Realist Approach. London: Routledge.

Stanley L \& Wise S (editors) (1990) Method, methodology and epistemology in feminist research processes. In Feminist Praxis: Research, Theory and Epistemology in Feminist Sociology, pp. 20-60. London: Routledge.

Stanley L \& Wise S (1993) Breaking Out Again: Feminist Ontology and Epistemology, 2nd ed. London: Routledge. 